\title{
Editorial: Are You Independent?
}

A few years ago a newspaper was launched in Britain. It was called The Independent and as part of its initial publicity there was a poster which said 'It is Independent. Are You?' As a result of this poster a joke then started doing the rounds, which pictured clusters of people (in places such as school staff rooms, university common rooms, broadcasting studios and lawyers' chambers) all with copies of The Independent under their arms.

There is, though, a serious point underlying the joke. Rather grandly this might be called the paradox of independent thinking, 'independent thinking' being highly valued in the very places where Independent readers are to be found. In practice what is generally thought of (at least by the thinkers themselves) as independent (or sometimes autonomous or critical) thinking tends, like The Independent itself, to be anti-authoritarian, rationalistic, naturalistic, vaguely or not so vaguely anti-religious, internationalist, leftist in politics and liberal in social attitudes. Each of these positions can be defended. Most of them have been (increasingly) standard fare among intellectuals since the time of the Enlightenment; but the very prevalence of these attitudes among the educated classes does raise a question as to how far someone who thinks along these lines can properly be described as an 'independent' or 'autonomous' or 'critical' thinker.

Of course, all of us in our thinking are influenced by our upbringing, the people we associate with, our cultural and professional circumstances, the papers and books we read, and so on. Few of us can really be independent in our thinking; taking independence of thought to be genuine independence, maybe in any field of human endeavour there are at most a few dozen really independent thinkers each century or so, if that.

However a subversive thought suggests itself at this point: in the standard university common room (or philosophical seminar, even) might the more independent (autonomous, critical) thinker be someone who was authoritarian, irrationalist, hostile to science (in a Blakean way, perhaps), religious, nationalistic and conservative politically and socially? Rather against The Independent's pretensions, this might just go to show that being an independent (autonomous, critical) thinker is not necessarily an ideal to be pursued after all. 